\title{
Fatal Outcome of Accidental Vitamin D Overdose
}

\author{
Praveen Narsaria $^{1} \cdot$ Jhuma Sankar $^{1} \cdot$ Rakesh Lodha $^{1}$
}

Received: 25 August 2015 / Accepted: 6 April 2016/Published online: 27 April 2016

(C) Dr. K C Chaudhuri Foundation 2016

To the Editor: In recent years vitamin D deficiency has been considered as the most common nutritional deficiency in health and disease [1] and hence, there has been an increase in the use of vitamin D. Death due to vitamin D toxicity has not been reported. We present here a case of accidental Vitamin D overdose presenting with complications of hypercalcemia, affecting multiple organs and ultimately leading to death of the child.

A 10-y-old boy being treated for short stature (weight for age and height for age $<-3 \mathrm{Z}$ score) in a rural health facility inadvertently received 6 lakh IU of vitamin D daily for $21 \mathrm{~d}$ instead of growth hormone due to erroneous prescription. Subsequently, he developed abdominal pain and vomiting and a possibility of iatrogenic vitamin D intoxication was kept, which was confirmed by elevated levels of $25 \mathrm{OH}$ vitamin $\mathrm{D}(>160 \mathrm{ng} / \mathrm{ml})$ and suppressed PTH level $(5.34 \mathrm{pcg} / \mathrm{ml})$. Hypercalcemia was managed with IV hydration, furosemide, steroids, calcitonin and pamidronate and the child was discharged on prednisolone. Following this, he was readmitted twice and managed similarly. However, in the last admission, he had hypertensive encephalopathy with pulmonary edema requiring IV nitroprusside infusion, mechanical ventilation and hemodialysis. The CT brain was suggestive of posterior reversible leucoencephalopathy syndrome. He was also noted to have a tender epigastric lump which was diagnosed to be due to hypercalcemia induced acute pancreatitis. Throughout his PICU stay, there was no improvement in his clinical condition and his calcium levels continued to remain

Jhuma Sankar

jhumaji@gmail.com

1 Department of Pediatrics, All India Institute of Medical Sciences, New Delhi 110029, India above $14 \mathrm{~g} / \mathrm{dl}$ despite hemodialysis. The child succumbed to his illness complicated by nosocomial sepsis and shock.

There are few reports of hypervitaminosis D [2-5]. Some of the causes reported include over-fortification of milk [2], over the counter vitamin D supplements [3] and dosing errors [4]. This child received 30 times the recommended dosage of vitamin D [5]. This inadvertent overdosing resulted in hypercalcemia and its complications which remained refractory to therapy till the end. This case highlights the risks involved with vitamin $\mathrm{D}$ administration, particularly parenteral route and that its intoxication can be fatal.

Acknowledgments We thank Dr. Santosh Rathia for his assistance in management of the patient and also extend our deep appreciation to all the PICU staff at AIIMS for their contributions.

\section{Compliance with Ethical Standards}

Conflict of Interest None.

Source of Funding None.

\section{References}

1. Holick MF. Vitamin D: extraskeletal health. Rheum Dis Clin N Am. 2012;38:141-60.

2. Blank S, Scanlon KS, Sinks TH, Lett S, Falk H. An outbreak of hypervitaminosis D associated with the overfortification of milk from a home-delivery dairy. Am J Public Health. 1995;85:656-9.

3. Klontz KC, Acheson DW. Dietary supplement-induced vitamin D intoxication. N Engl J Med. 2007;357:308-9.

4. Barrueto F, Wang-Flores HH, Howland MA, et al. Acute vitamin D intoxication in a child. Pediatrics. 2005;116:e453-6.

5. Holick MF, Binkley NC, Bischoff-Ferrari HA, et al. Evaluation, treatment, and prevention of vitamin d deficiency: an endocrine society clinical practice guideline. J Clin Endocrinol Metab 2011;96:1911-30. 